\title{
Comparison of built environment adaptations to heat exposure and mortality during hot weather, West Midlands region, UK
}

Jonathon Taylor ${ }^{\mathrm{a}}$, Paul Wilkinson ${ }^{\mathrm{b}}$, Roberto Picetti ${ }^{\mathrm{b}}$, Phil Symonds ${ }^{\mathrm{a}}$, Clare Heaviside ${ }^{\mathrm{b}, \mathrm{c}}$, Helen Macintyre ${ }^{c}$, Michael Davies ${ }^{a}$, Anna Mavrogianni ${ }^{a}$, Emma Hutchinson $^{b}$

a UCL Institute of Environmental Design and Engineering, Central House, 14 Upper Woburn Place, London, UK, WC1H ONN

${ }^{b}$ Department of Social and Environmental Health Research, London School of Hygiene and Tropical Medicine, Keppel Street, London, UK, WC1E 7HT

${ }^{c}$ Centre for Radiation, Chemical and Environmental Hazards, Public Health England, Chilton, UK, OX11 ORQ

Address for correspondence: Dr Jonathon Taylor, UCL Institute of Environmental Design and Engineering, Central House, 14 Upper Woburn Place, London, UK, WC1H ONN. Email: j.g.taylor@ucl.ac.uk 


\section{ABSTRACT}

There is growing recognition of the need to improve protection against the adverse health effects of hot weather in the context of climate change. We quantify the impact of the Urban Heat Island (UHI) and selected adaptation measures made to dwellings on temperature exposure and mortality in the West Midlands region of the UK. We used 1) building physics models to assess indoor temperatures, initially in the existing housing stock and then following adaptation measures (energy efficiency building fabric upgrades and/or window shutters), of representative dwelling archetypes using data from the English Housing Survey (EHS), and 2) Modelled UHI effect on outdoor temperatures. The ages of residents were combined with evidence on the heat-mortality relationship to estimate mortality risk and to quantify population-level changes in risk following adaptations to reduce summertime heat exposure. Results indicate that the UHI effect accounts for an estimated $21 \%$ of mortality. External shutters may reduce heat-related mortality by $30-60 \%$ depending on weather conditions, while shutters in conjunction with energy-efficient retrofitting may reduce risk by up to $52 \%$. The use of shutters appears to be one of the most effective measures providing protection against heat-related mortality during periods of high summer temperatures, although their effectiveness may be limited under extreme temperatures. Energy efficiency adaptations to the dwellings and measures to increase green space in the urban environment to combat the UHI effect appear to be less beneficial for reducing heat-related mortality.

Keywords heat; mortality; adaptation; dwellings; indoor temperature; urban heat island

\section{Highlights}

- Built environment characteristics may affect population exposure to excess heat

- Housing and land surface changes may alter heat exposure and heat-related mortality

- Installing external shutters may reduce heat-attributable deaths by $30-60 \%$

- Shutter installation and energy efficiency retrofit may reduce mortality by $52 \%$

- The Urban Heat Island may contribute to $21 \%$ of heat mortality 


\section{INTRODUCTION}

The evidence that climate change will increase ambient temperatures in the UK, as elsewhere, has focused attention on how to protect against the health risks of summer heat. In England and Wales, heatwaves in 2003 and 2006 were associated with 2,000 and 680 excess deaths, respectively (Johnson et al., 2005; PHE, 2015). These will not be exceptional events by mid-century (Murphy et al., 2009), and potential vulnerability to similar heatwaves is expected to increase as the population ages (Gasparrini et al., 2012; Hajat et al., 2014).

Among the possible measures to protect against such risks are adaptation of the housing stock to reduce indoor temperatures and actions aimed at reducing the Urban Heat Island (UHI) effect. Indoor heat exposures are likely important, given that the English population is estimated to spend $70 \%$ of their time in their own homes, increasing to $82 \%$ in the elderly population (ONS, 2005). As in many temperate regions around the world, buildings in England have not been designed for high outdoor temperatures, and English dwellings vary in their response to high external temperatures (Beizaee et al., 2013; Mavrogianni et al., 2012) with overheating in housing considered a future risk (Vardoulakis et al., 2015). Potential dwelling adaptation measures to reduce indoor overheating include external shutters, shading, high albedo surfaces, and low-e glazing (Gupta and Gregg, 2013). In addition, there is a critical need to reduce the carbon emissions of the housing stock through energy-efficient retrofits of existing dwellings, which may impact on dwelling overheating risks (Mavrogianni et al., 2012; Taylor et al., 2015). The UHI effect describes the occurrence of higher outdoor temperatures in metropolitan areas compared with those of the surrounding countryside. It is caused by the thermal properties (heat absorption, capacity, conductance and albedo) of the surfaces and materials found in urban landscapes, the reduced evapotranspiration from reduced natural vegetation and increased impervious surfaces, and the waste heat production from anthropogenic activities (Oke, 1982). Urban land use changes are therefore a primary means for UHI mitigation (Heaviside et al. 2017).

The relationship between heat and excess mortality in the UK has been derived for different regions (Armstrong et al, 2011), and age classifications (Gasparrini et al, 2012) using a two-day rolling mean maximum outdoor temperature. Hajat et al $(2007,2014)$ also derived regional relationships between excess mortality and heat for England, instead using two-day mean daily outdoor temperature. Estimates of the relationship between indoor temperatures and heat-related mortality in the UK have heretofore relied on the application of the above models to make estimates of indoor temperature exposure. Such studies include Taylor et al (2015), who estimated the spatial variation of summertime mortality across London using building physics-derived indoor temperatures and modelled UHI temperatures; and Liu et al (2017), who used building physics models and high spatial resolution climate projections to map heat mortality risk across the city of Sheffield under current and future conditions. Similarly, the spatial variation of UHI-related mortality has been estimated using the Hajat model and simulated outdoor temperatures for the West Midlands by Heaviside et al (2016). 
The impact that housing heat adaptation, energy efficient retrofit, and the UHI may have on temperature exposure and mortality risk remains a focus of continuing research. In this paper, we use modelling methods that draw on current evidence to quantify the potential impact of external shutters, complete energy efficiency retrofit, and the UHI, using the West Midlands region of the UK as the setting. The West Midlands is a region of 5.6 million people (ONS, 2011) comprising the city of Birmingham and the West Midlands conurbation (which includes the city of Wolverhampton and the towns of Dudley, Solihull, Walsall and West Bromwich).

\section{METHODS}

The study is based on a set of in silico experiments to estimate the impact on population temperature exposure and subsequent heat-related mortality of:

(1) Energy efficiency upgrades to the entire housing stock, including the installation of floor, roof, and wall insulation, triple glazed windows, and a corresponding increase in air tightness;

(2) The installation of external shutters/shading in the entire stock, assumed to be used in all dwellings between 9 a.m. and 6 p.m. during the summer months; and

(3) The UHI effect, estimated by assuming all current built structures (including all buildings, roads and artificial surfaces) are replaced by natural vegetation.

Implementing housing adaptations across the entire stock is ambitious, and are specified to represent the theoretical upper limit of the impacts on temperature exposure and health of these types of intervention. The removal of urban surfaces is an unrealistic adaptation, and would indeed result in a significantly reduced exposed population; therefore, this is presented as an investigation of mortality attributable to the UHI rather than an adaptation. The steps entailed in the quantification of the impact of the adaptation measures are shown schematically in Figure 1. For the adaptations above, the steps were:

(1) The use of a) building physics simulation studies to generate patterns of indoor temperatures based on different outdoor temperatures for a representative sample of dwellings in the region, or b) regional meteorological models to generate spatial and temporal variations in UHI;

(2) The use of these data to estimate a 'temperature anomaly' for each individual in the West Midlands population to quantify temperature exposure modification. These are defined as a) the difference between the average indoor temperature of an individual's dwelling and the regional populationaverage indoor temperature exposure, or b) the difference between an individual's outdoor temperature exposure and the regional populationaverage outdoor temperature. 
(3) The use of published (outdoor) temperature-mortality relationships (Armstrong et al., 2011) - previously used in studies that use modelled indoor temperatures in England (Taylor et al., 2015; Liu et at, 2017) - to quantify the associated impact of summer heat on deaths. Here, it assumes that adaptation-related changes to the temperature anomaly defined in (2) lead to a corresponding shift in personal temperature exposure.

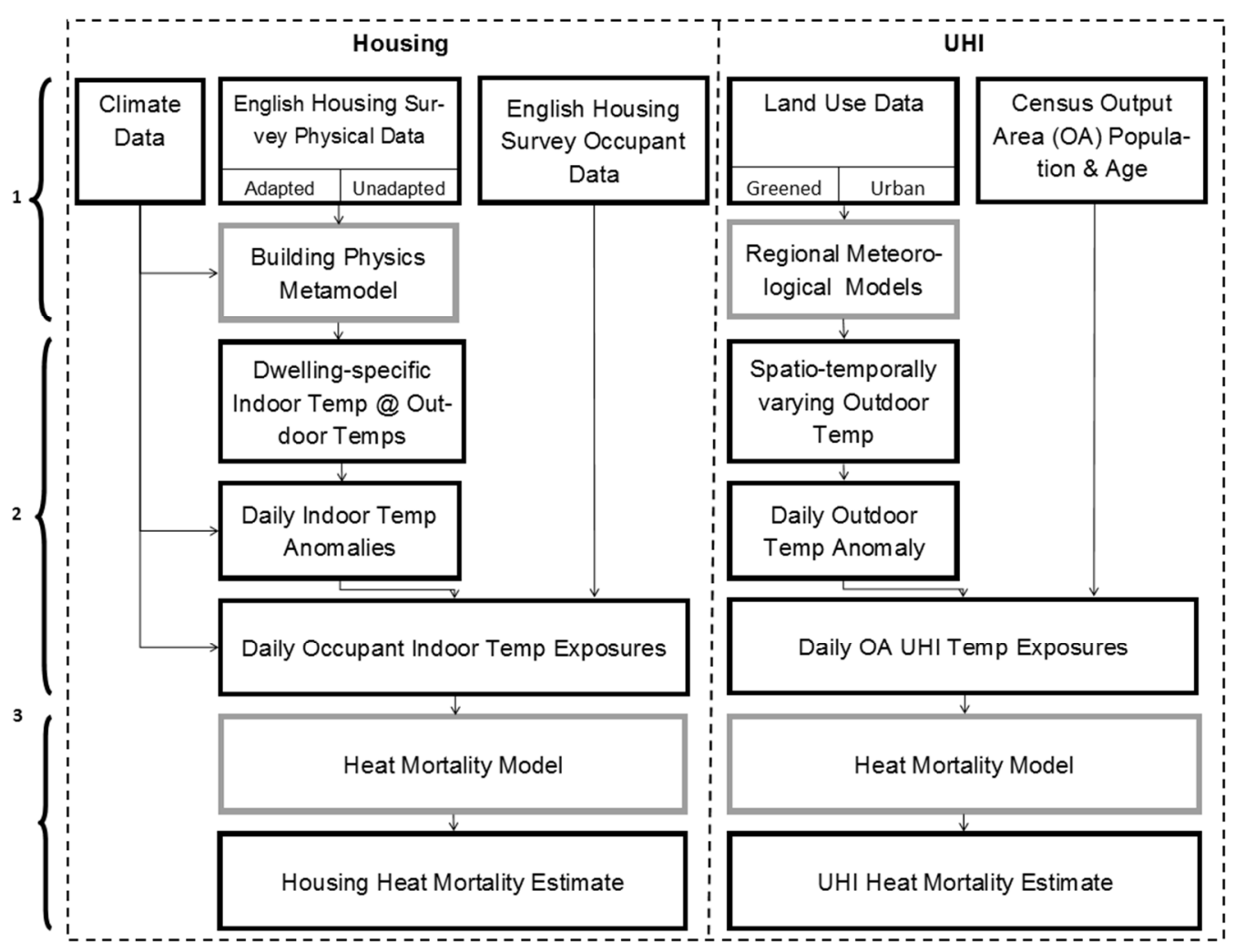

Figure 1. Flow diagram for steps 1-3 of the indoor and UHI heat mortality calculation.

\subsection{Modelling indoor temperatures and dwelling type-specific temperature anomaly}

Indoor temperatures for each of the 1,558 West Midlands region dwellings included in the statistically-representative 2010-11 English Housing Survey (EHS)(DCLG, 2011) were estimated using a metamodel that predicts (using a limited set of dwelling characteristics) indoor temperatures simulated by the validated building physics model EnergyPlus using detailed dwelling data (Symonds et al., 2016a). The steps were as follows.

First, EnergyPlus, was used to simulate hourly indoor (living room) temperatures across a calendar year for each of the 14 dwelling archetypes listed in Table 1. We 
used Latin Hypercube sampling to select, for each dwelling type, random combinations of the other dwelling characteristics listed in Table 1 (wall construction, surrounding terrain, orientation, permeability, U-values, glazing ratio, ceiling height and floor area) as the data inputs for the model runs. This generated a total of 19,200 simulations with unique dwelling type/characteristics combinations. These simulations were run using UK Climate Projections (UKCP09) baseline weather data from the Birmingham airport monitoring station for the year with the fourth hottest summer over the period 1961 to 1990 (1970), chosen to represent the conditions of a warm, but not extreme, summer under 'base' climatic conditions (Eames et al., 2010). A neural network metamodel was then developed using the Python tool PyBrain (Schaul et al., 2010) to predict the average of the simulated daily two-day rolling mean maximum living room temperatures $\left(T_{\text {max }, i n}\right)$ within incremental ranges of two-day rolling mean maximum outdoor temperatures $\left(T_{\text {max }, \text { out }}\right)$ for each dwelling type (Symonds et al., 2016a).

Table 1. Variants of dwelling characteristics used in modelling indoor temperatures.

\begin{tabular}{|c|c|c|}
\hline Characteristic & $\begin{array}{l}\text { Variants or assumed range of values used in } \\
\text { modelling }\end{array}$ & $\begin{array}{l}\text { Dwellings in West Midlands } \\
\text { Region estimated from 2011-12 } \\
\text { EHS. } \\
\text { Number (percent) or mean (IQR) }\end{array}$ \\
\hline \multirow{14}{*}{$\begin{array}{l}\text { Building archetypes } \\
\text { (14 variants) }\end{array}$} & 1 End Terrace & $215,455(9.6 \%)$ \\
\hline & 2 Mid Terrace & $391,393(17.5 \%)$ \\
\hline & 3 Semi Detached & $711,104(31.8 \%)$ \\
\hline & 4 Detached & $441,126(19.7 \%)$ \\
\hline & 5 Bungalow & $172,169(7.7 \%)$ \\
\hline & 6 Converted Flats & $8049(0.36 \%)$ \\
\hline & 7 Converted Flats & $6961(0.31 \%)$ \\
\hline & Ground \& basement & $17,670(0.76 \%)$ \\
\hline & 9 Low rise Flats Top floor & $100,935(4.51 \%)$ \\
\hline & 10 Low rise Flats Middle floor & $36,029(1.61 \%)$ \\
\hline & 11 Low rise Flats Ground floor & $99,138(4.4 \%)$ \\
\hline & 12 High rise Flats Top floor & $11,210(0.5 \%)$ \\
\hline & 13 High rise Flats Middle floor & $26,529(1.2 \%)$ \\
\hline & 14 High rise Flats Ground floor & $2,194(0.1 \%)$ \\
\hline \multirow{2}{*}{$\begin{array}{l}\text { Wall construction } \\
\text { ( } 2 \text { variants) }\end{array}$} & 1 Solid wall & $688,171(31 \%)$ \\
\hline & 2 Cavity wall & $1,551,791(69 \%)$ \\
\hline \multirow{3}{*}{$\begin{array}{l}\text { Surrounding Terrain } \\
\text { (3 variants) }\end{array}$} & 1 City & $1,865,081(83 \%)$ \\
\hline & 2 Urban & $280,564(13 \%)$ \\
\hline & 3 Rural & $94,317(4 \%)$ \\
\hline \multirow{4}{*}{$\begin{array}{l}\text { Orientation of front } \\
\text { façade } \\
\text { (4 variants) }\end{array}$} & 1 North & \multirow{4}{*}{$\begin{array}{c}\text { Assumed to be average of all four } \\
\text { orientations }\end{array}$} \\
\hline & 2 East & \\
\hline & 3 South & \\
\hline & 4 West & \\
\hline Permeability & Range: 0 to $\infty \mathrm{m}^{3} / \mathrm{h} / \mathrm{m}^{2}(\mu=20, \sigma=10)$ & $16.1 \mathrm{~m}^{3} / \mathrm{h} / \mathrm{m}^{2}(13.9-17.9)$ \\
\hline U-value: Wall & Range: 0.15 to $2.55 \mathrm{~W} / \mathrm{m}^{2} \mathrm{~K}$ & $1.16 \mathrm{~W} / \mathrm{m}^{2} \mathrm{~K}(0.5-2.1)$ \\
\hline Floor & Range: 0.15 to $1.30 \mathrm{~W} / \mathrm{m}^{2} \mathrm{~K}$ & $0.66 \mathrm{~W} / \mathrm{m}^{2} \mathrm{~K}(0.62-0.78)$ \\
\hline Window & Range: 0.85 to $4.80 \mathrm{~W} / \mathrm{m}^{2} \mathrm{~K}$ & $2.9 \mathrm{~W} / \mathrm{m}^{2} \mathrm{~K}(2.76-2.76)$ \\
\hline
\end{tabular}




\begin{tabular}{llc}
$\quad$ Roof & Range: 0.10 to $2.25 \mathrm{~W} / \mathrm{m}^{2} \mathrm{~K}$ & $0.61 \mathrm{~W} / \mathrm{m}^{2} \mathrm{~K}(0.22-0.50)$ \\
Glazing ratio & Range: 0 to 1 & $0.29(0.20-0.34)$ \\
Ceiling height & Range: 2 to 3 \\
Floor size & $\begin{array}{l}\text { Range: } 0.65^{*} \mu \text { to } 2 * \mu(\mu=\text { mean area per } \\
\text { archetype variant) }\end{array}$ & $2.4 \mathrm{~m}(2.3-2.5)$ \\
\hline
\end{tabular}

NB. Occupants were assumed to open windows when indoor temperatures exceeded $22^{\circ} \mathrm{C}$, except when outdoor temperatures exceeded indoor temperatures. Opening fraction was assumed to be $1 / 3$.

The metamodel outputs were then used to estimate the daily $T_{\text {max } \text {,in }}$ for each West Midlands dwelling in the EHS for the summer (1 May to 31 August) using the daily $T_{\text {max }}$ out of the base weather file. From this, a dwelling-specific daily temperature anomaly was calculated:

$$
T_{\text {max }, \text { anomaly }}=T_{\text {max }, \text { in }}-\overline{T_{\max , \text { in }}}
$$

Where $T_{\max , i n}$ is the dwelling-specific temperature for a given day, $\overline{T_{\max } \text {,in }}$ is the occupant-weighted mean $T_{\text {max, in }}$ for the region as a whole (calculated using EHS household occupancies and weighting values), and $T_{\text {max, anomaly }}$ represents the building's positive or negative indoor anomaly relative to the regional mean.

These estimates of temperature anomaly were derived for each dwelling assuming no adaptations and then after each of the two forms of adaptation described above: i.e. (1) full energy efficiency retrofit to all dwellings, including cavity and/or internal solid wall insulation, loft and floor insulation, triple glazed windows, and airtightening equivalent to reducing permeability ${ }^{1}$ by $5 \mathrm{~m}^{3} / \mathrm{h} / \mathrm{m}^{2}$ and (2) application of shutters/shading to all dwellings from 9 am to $6 \mathrm{pm}$. In both 1) and 2), dwellingspecific anomalies were calculated relative to the mean of the un-adapted stock. Active cooling measures such as air conditioning (A/C) or ceiling fans were not considered due to their energy demand, and - in the case of $A / C$ - the assumption that the ideal operation of $A / C$ installed across the stock would reduce heat mortality risk to very low levels.

Further temperature estimates (and hence classifications of the temperature anomaly) were carried out using the metamodel outputs as well as (1) the population-weighted average of modelled weather data from the heatwave ${ }^{2}$ of 1-10 August 2003, taken to represent an extreme summer of the 'current' climate (see below), and (2) future weather data derived using UKCP09 representing a typical

\footnotetext{
${ }^{1}$ Permeability is defined here as the volume of air leakage through the building envelope per hour at 50Pa pressure differential.

${ }^{2}$ The UK does not have an official definition of a heatwave, however the World Meteorological Organization definition of "five consecutive days that exceed the average maximum temperature by $5^{\circ} \mathrm{C}^{\prime \prime}$ is typically used. While this criterion was not met in the West Midlands, this period is generally referred to as a heatwave in preceding literature.
} 
summer (1 May to 31 August) in each of the years 2030, 2050, 2080 (medium emissions, 90\% probability) (Eames et al., 2010). This provided a range of estimates from 'warm' to 'extreme' summer scenarios.

\subsection{Urban heat island (UHI) temperature increments}

The regional meteorological modelling of the UHI is described in Heaviside et al (2015). Briefly, to estimate the effect of the UHI on outdoor temperatures we used the Weather Research and Forecasting (WRF, version 3.6.1) meteorological model (Chen et al., 2011) to simulate hourly ambient air temperatures at a height of 2 metres above ground, with a spatial resolution of $1 \mathrm{~km} \times 1 \mathrm{~km}$ across the West Midlands. The model includes a detailed land surface scheme, and representation of urban structures' influence on air flow and energy fluxes within the urban canopy (Martilli et al., 2002). This modelled data was used to calculate daily $T_{\max , o u t}$ across the West Midlands region for the 2003 heatwave (1-10 August) under two scenarios: 1) a model that included detailed urban land use and building geometry data for the region, and 2) a model in which urban surfaces were removed and replaced by natural vegetation (grassland and pasture). The temperature difference between these two simulations (with and without urban surfaces) allows an estimation of the $\mathrm{UHI}$ intensity across the region. This data has been used previously to calculate the total UHI-attributable mortality using a different heat-mortality model and associated heat-risk coefficients, and underlying population data (Heaviside et al., 2016).

In this study, ArcGIS (ESRI, 2013) was used to overlay the WRF model outputs with 2001 Census Output Area (OA)(ONS, 2001) population age and gender data, which is the population data that best corresponds to the 2010-2011 EHS and the 2003 heatwave. Using equation 1 as a basis, an OA-specific daily UHI temperature anomaly was estimated as the difference between the $T_{\text {max }, \text { out }}$ of an OA and the Census population-weighted regional mean $T_{\max , \text { out }}$ for both scenarios. As with buildings, anomalies with urban surfaces removed were calculated relative to unadapted population-weighted means.

\subsection{Mortality Calculations}

Calculations of heat-related mortality were based on published region-specific temperature-mortality functions for the West Midlands (Armstrong et al., 2011). These functions represent the relationship between $T_{\max , \text { out }}$ and mortality. Heatrelated mortality calculations were carried out separately for dwelling and UHI scenarios following the method described in Taylor et al, (2015) under the assumption that the temperature-mortality relationship is the same for indoor temperatures as it is for outdoor temperatures.

For the residents in each dwelling type, temperature exposure was taken to be the outdoor temperature modified by the dwelling-specific temperature anomaly: 


$$
T_{\max , p}=T_{\max , \text { out }}+T_{\max , \text { anomaly }}
$$

where $T_{\max , p}$ is the daily temperature exposure for a dwelling occupant $p$. An assumption of these calculations, therefore, is that the dwelling specific temperature anomaly (which has mean of zero for the un-adapted stock) reflects dwelling-todwelling (and household-to-household) variation in temperature exposure about the regional average. For the UHI, $T_{\max , p}$ was taken to be the population-weighted average outdoor temperature $\left(T_{\max , \text { out }}\right)$ plus the OA-specific temperature anomaly.

For the calculations of mortality risk, we used underlying age-specific all-cause mortality rates for 2012 obtained from the Office for National Statistics (ONS)(2013), adjusted for seasonality to yield a daily average death rate for the summer months (May to August) (Table 2). We then used age-specific temperature-mortality coefficients, derived by adjusting the all-ages coefficient for the West Midlands $\left(2.20 \%\right.$ per ${ }^{\circ} \mathrm{C}$ ) (Armstrong et al, 2011) in proportion to the age-specific (0-64, 65-74, $75-84,85+)$ relative risks for England and Wales that were estimated by Gasparrini et al (2012) using the same method as the aforementioned Armstrong study (Table 2). 
Table 2. Background mortality data for the West Midlands, including annual risk of mortality per thousand population for different age classifications; the fraction adjustment of annual mortality to reflect reduced summertime mortality rates for these age classifications; and the age-specific relative risk $\left(R R_{i}\right)$ of mortality per ${ }^{\circ} \mathrm{C}$ for the West Midlands for broad age classifications.

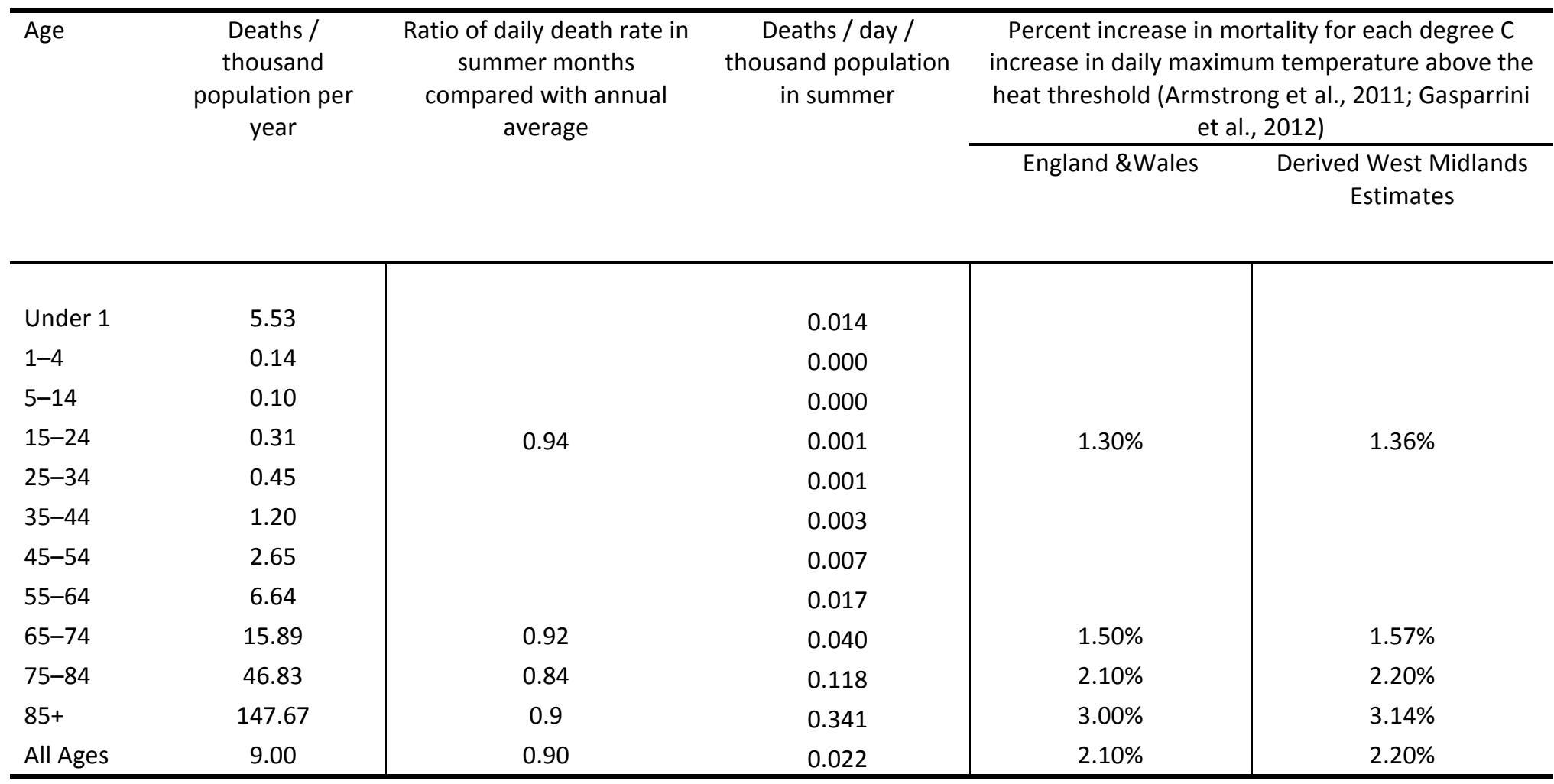


For a given day, the excess mortality for person $p$ of age $i$ was calculated as:

$$
\text { Excess Mortality }_{p}=\left(T_{\text {max }, p}-T_{\text {heat }}\right) \times\left(R R_{i}-1\right) \times M_{i}
$$

where $R R_{i}$ is the age-specific relative risk for a 1 degree Celsius increase in temperature above the region-specific heat threshold $\left(T_{\text {heat }}\right)$, and $M_{i}$ is age-specific background mortality rate for the summer period. In the West Midlands, $T_{\text {heat }}$ occurs at the $93^{\text {rd }}$ percentile $T_{\text {max, out }}$, or $23.0^{\circ} \mathrm{C}$ (Armstrong et al, 2011).

Daily mortality risk for each dwelling occupant was summed over the modelled period and across all households using household weighting values to yield regional total mortality estimates. Calculations were repeated for each climate and adaptation scenario. As future scenarios are modelled without demographic or housing stock changes, they represent projections of temperature exposures under increasingly hot summers rather than predictions of future mortality. For the UHI, mortality calculations were summed over the 10-day hot spell and contrasted with dwelling occupant risk over the same period.

\section{RESULTS}

\subsection{Population temperature exposures and heat mortality}

Distributions of estimated temperatures and heat-related mortality impacts with and without heat or energy efficiency adaptation measures are summarized in Table 3 (current climate warm summer) and Table 4 (2003 10-day heat wave).

\section{Current climate warm summer}

- No adaptation shows a regional mean temperature anomaly of zero - by definition - with anomalies of the individual dwelling in the housing stock ranging from $-2.9^{\circ} \mathrm{C}$ to $+4^{\circ} \mathrm{C}$ at outdoor temperatures above $T_{\text {heat }}$.

- There is a small increase in mean anomaly with retrofit $\left(0.26^{\circ} \mathrm{C}\right)$ and hence in the distribution of $T_{\max , p}$. There is also a small increase in the frequency of $T_{\max , p}$ exceedance of the regional mortality threshold, $T_{\text {heat }}$.

- There was a much larger protective shift with installation of shutters, with a decrease of mean anomaly of $-1.8^{\circ} \mathrm{C}$ and a decrease in the number of days $T_{\text {max }, p}$ exceeds $T_{\text {heat }}$.

- Shutters maintained their protective effect when used in conjunction with energy efficient retrofits.

- The effect of adaptations on the number and percent of deaths attributable to heat mirror the patterns of temperature shift, with full retrofit leading to a mortality increase of $14 \%$, shutters leading to a decrease of $60 \%$, and combined retrofit and shutters decreasing mortality by $52 \%$. 
- Though the 2003 example is an unusual event, for the West Midlands region under the current climate, temperatures were not extreme.

- The heatwave lasted only 10 days, during which only the last 7 (70\%) consecutive days had outdoor temperatures that exceeded $T_{\text {heat }}$.

- Again, there were small positive shifts in mean anomaly with retrofit $\left(0.4^{\circ} \mathrm{C}\right)$ and hence in the distribution of $T_{\max , p}$.

- There was a protective shift with external shutters $\left(-0.9^{\circ} \mathrm{C}\right)$, although the protective effect was less than under the current warm summer scenario.

- There was a relatively large shift in anomaly attributable to the UHI $\left(1.0^{\circ} \mathrm{C}\right)$. While removal of all urban surfaces is unrealistic, modest changes to urban greening - such as an increase in green roofs, lower albedo pavements, and green infrastructure development - would be achievable in practice and the impact in personal temperature exposure and mortality risk correspondingly smaller.

- The effect of building adaptations on the number and percent of deaths attributable to heat mirror the patterns of temperature shift, with retrofit increasing mortality (1\%) and shutters decreasing mortality (30\%). While the $\mathrm{UHI}$ resulted in the largest shift in mean anomaly, it did not have a correspondingly large impact on mortality (21\%) as the largest changes in temperature exposure occurred in locations with lower populations of the vulnerable elderly. 
Table 3. Temperatures and estimated heat-related mortality impacts during summer (MJJA) months with and without adaptation: results based on temperature distribution for a baseline climate, warm summer. *

\begin{tabular}{|c|c|c|c|c|}
\hline & \multirow[b]{2}{*}{ No adaptation } & \multicolumn{3}{|c|}{ After adaptation: } \\
\hline & & Retrofit & Shutters/shading & Combined \\
\hline Maximum outdoor daily temperature $\left({ }^{\circ} \mathrm{C}\right)$ : mean and (IQR) & \multicolumn{4}{|c|}{24.5 (23.1 to 25.9$)$} \\
\hline Number (\%) of summer days when outdoor $T_{\max , \text { out }}$ exceeds $T_{\text {heat }}$ & \multicolumn{4}{|c|}{$23(18.7 \%)$} \\
\hline $\begin{array}{l}\text { Dwelling-specific temperature anomaly, } T_{\max } \text {,anomaly, }\left({ }^{\circ} \mathrm{C}\right) \text { relative to } \\
\text { the regional average: mean }\left(5^{\text {th }} \text { and } 95^{\text {th }} \text { percentile) }\right.\end{array}$ & $\begin{array}{c}0 \\
(-1.16 \text { to } 1.27)\end{array}$ & $\begin{array}{c}0.26 \\
(-1.02 \text { to } 1.72)\end{array}$ & $\begin{array}{c}-1.77 \\
(-2.61 \text { to }-0.04)\end{array}$ & $\begin{array}{c}-1.06 \\
(-2.22 \text { to } 0.23)\end{array}$ \\
\hline $\begin{array}{l}\text { Person-specific estimate of the mean of the daily maximum indoor } \\
\text { temperature }\left({ }^{\circ} \mathrm{C}\right) \text { for the summer period, } T_{\max , p} \text { : mean (IQR) }\end{array}$ & $\begin{array}{c}24.4 \\
(23.8 \text { to } 24.8)\end{array}$ & $\begin{array}{c}24.6 \\
(24.0 \text { to } 25.2)\end{array}$ & $\begin{array}{c}23.1 \\
(22.6 \text { to } 23.6)\end{array}$ & $\begin{array}{c}23.2 \\
(22.8 \text { to } 233.8)\end{array}$ \\
\hline Percent (IQR) of summer days when $T_{\max , p}$ exceeds $T_{\text {heat }}$ & $\begin{array}{c}18.7 \% \\
(13.8 \text { to } 21.1)\end{array}$ & $\begin{array}{c}21.1 \% \\
(17.1 \text { to } 26.0)\end{array}$ & $\begin{array}{c}9.3 \% \\
(5.7 \text { to } 12.2)\end{array}$ & $\begin{array}{l}10.8 \% \\
(5.7 \text { to } 13.8)\end{array}$ \\
\hline \multicolumn{5}{|l|}{ Mortality: } \\
\hline Deaths $/ 1,000,000$ during summer (MJJA) period & 2412 & 2414 & 2404 & 2405 \\
\hline deaths $(\%)$ attributable to heat & $0.6 \%$ & $0.6 \%$ & $0.2 \%$ & $0.3 \%$ \\
\hline excess number (\%) of heat deaths relative to no intervention & -- & $14 \%$ & $-60 \%$ & $-52 \%$ \\
\hline
\end{tabular}

* Temperatures of the fourth warmest summer over the period 1961 to 1990. 
Table 4. Temperatures and estimated heat-related mortality impacts during the 10 day 2003 heatwave with and without building adaptations or urban surfaces.

\begin{tabular}{|c|c|c|c|c|}
\hline & \multicolumn{4}{|c|}{ After adaptation: } \\
\hline & No adaptation & Retrofit & Shutters/shading & $\begin{array}{l}\text { Removal of urban } \\
\text { surfaces }\end{array}$ \\
\hline Maximum outdoor daily temperature $\left({ }^{\circ} \mathrm{C}\right)$ : mean and $(\mathrm{IQR})$ & \multicolumn{4}{|c|}{$28.4(26.8,30.3)$} \\
\hline Number (\%) of days when outdoor $T_{\max , \text { out }}$ exceeds $T_{\text {heat }}$ & \multicolumn{4}{|c|}{$7(70 \%)$} \\
\hline $\begin{array}{l}\text { Temperature anomaly }\left(T_{\max } \text {, anomaly }\right),\left({ }^{\circ} \mathrm{C}\right) \text { : regional mean and }\left(5^{\text {th }}\right. \\
\left.\text { and } 95^{\text {th }} \text { percentile }\right)\end{array}$ & $0(-1.57$ to 1.62$)$ & $\begin{array}{l}0.40(-0.61 \text { to } \\
1.61)\end{array}$ & $\begin{array}{l}-0.88(-2.16 \text { to } \\
0.23)\end{array}$ & $\begin{array}{l}-1.0(-1.73 \text { to }- \\
0.24)\end{array}$ \\
\hline$T_{\max , p},\left({ }^{\circ} \mathrm{C}\right):$ mean (IQR) & $\begin{array}{l}28.0(27.42 \text { to } \\
28.6)\end{array}$ & $\begin{array}{l}28.1(27.3 \text { to } \\
28.8)\end{array}$ & 26.4 (25.9 to 27.0$)$ & $26.9(26.6$ to 27.3$)$ \\
\hline \multicolumn{5}{|l|}{ Mortality: } \\
\hline deaths $/ 100,000$ during heatwave & 209 & 209 & 205 & 207 \\
\hline deaths (\%) attributable to heat & $6.8 \%$ & $6.9 \%$ & $4.9 \%$ & $5.7 \%$ \\
\hline excess number (\%) of heat deaths relative to no intervention & -- & $1 \%$ & $-30 \%$ & $-20.6 \%$ \\
\hline
\end{tabular}




\subsection{Temperatures and heat mortality under future climates}

The effectiveness (and limits to the effectiveness) of the most protective adaptation measures, use of shutters and shading, under future climate change is explored in Figure 2.

- Figure $2 \mathrm{~A}$ shows the personal temperature distributions $\left(T_{\max , p}\right)$ for the current climate and 2030, 2050 and 2080 climates assuming a medium emissions scenario and a $90 \%$ probability of occurring relative to $T_{\text {heat }}$ (dotted line).

- Figure $2 \mathrm{~B}$ shows the corresponding impact on mortality with and without adaptation under the increasing temperatures of the climate scenarios.

At moderate temperatures, shutters are most effective at reducing mortality due to the potential to reduce $T_{\max , p}$ below the regional mortality threshold, while energy efficient retrofits demonstrate an opposite effect. The protective (shutters) and adverse (retrofit) effects on heat mortality are reduced under hotter climates due to this threshold effect, with temperatures exceeding the regional mortality threshold more frequently and by a larger margin. While the effectiveness of shutters under increasing outdoor temperatures is reduced, the installation of shutters is still projected to reduce typical summertime mortality by $37.8 \%$ ( 177 individuals), $34.6 \%$ (221 individuals), and $29.3 \%$ (285 individuals) in climates representative of 2030, 2050 , and 2080, respectively. The UHI is presented as mortality without urban surfaces under increasing population-weighted average $T_{\max , p}$; the irregular scattering represents the spatial variation in daily $T_{\max , p}$ over OAs with a distribution of population sizes and age profiles. 

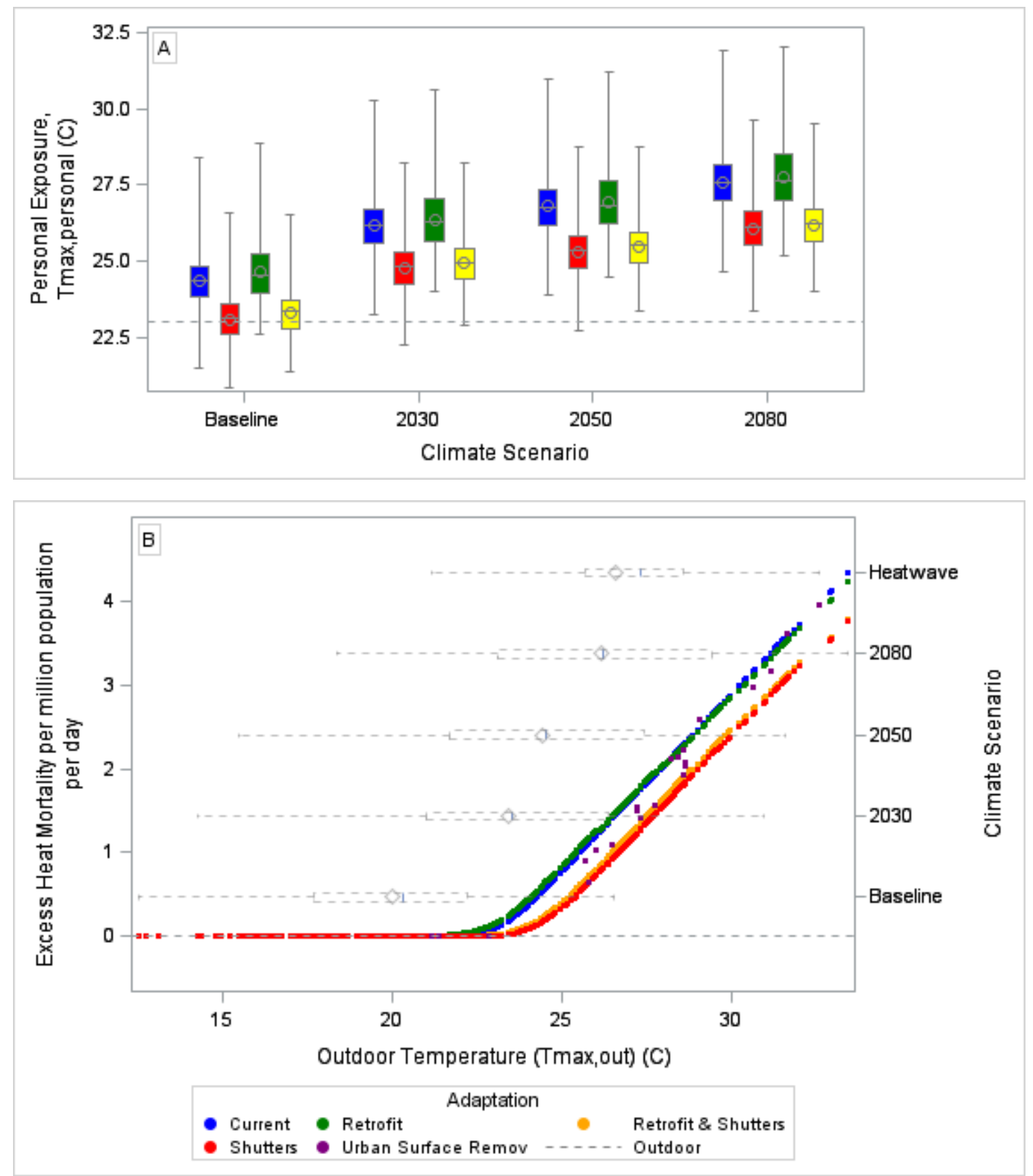

Figure 2. [A] Changes in the distribution of $T_{\max , p}$ by 2030, 2050 and 2080 for housing adaptation scenarios. The dotted line represents the regional heat mortality threshold ( $T_{\text {heat }}$ ) of 23C. [B] The estimated daily heat-related mortality per million population under increasing outdoor temperatures pre-and post-building and $\mathrm{UHI}$ adaptation (primary axis) and the distribution of observed and projected outdoor temperatures $\left(T_{\text {max }, \text { out }}\right)$ under different climate scenarios.

*These computations assume the population size and structure and underlying age-specific mortality rates remain unchanged at 2016 values

\section{DISCUSSION}

This paper provides new insights into the theoretical impacts of housing adaptations and the UHI on heat exposure and the risk of heat-related mortality. Of the scenarios modelled, shutters have the greatest potential to reduce mortality under moderate and increasing outdoor temperatures due to the reduction in both temperature exposure and the frequency with which the regional mortality threshold is exceeded. 
Complete energy efficient adaptation of the stock - including wall, roof, and floor insulation, triple glazed windows, and air-tightening were found to slightly increase mortality risk due to small increases in personal temperature exposures and the number of days on which the mortality threshold was exceeded. This was largely due to the installation of internal solid wall insulation and air-tightening, which may act to increase indoor temperatures (Taylor et al., 2015). In this study, solid walls were provided internal wall insulation in order to show a 'worst-case scenario' for retrofit overheating, however external wall insulation would likely offer the same energy benefits with a reduced risk of heat exposure. The small increase in summertime mortality post-adaptation is likely to be more than offset by a significant reduction in wintertime cold-related mortality due to warmer housing. Energy-efficient retrofits, when used in conjunction with shutters, offered the advantage of a reduction in both heat mortality risk as well as any anticipated reduction in building energy use. As we do not model demographic changes, changes to the housing stock, or potential population adaptation to heat, we do not presume to present a realistic prediction of mortality under future climates, but rather a projection of mortality under increasingly hot summers that are useful for quantifying hypothetical climate change impacts under these simplified scenarios.

The overall impact of the UHI on mortality was less than the potential reduction in mortality risk from building interventions, despite the UHI having a greater impact on population average $T_{\max , p}$. This may be due to spatial effects, where the largest reductions in $T_{\max , p}$ from the removal of urban surfaces occurred in urban areas with younger populations, while smaller reductions were seen in rural or suburban areas with relatively higher numbers of elderly residents. This indicates an advantage of shutters over UHI mitigation, as shutters may be installed as a targeted intervention for the most heat-vulnerable. The mortality calculations for the UHI differ significantly from those derived by Heaviside et al (2016), who using similar simulations estimated that the UHI effect was responsible for around $50 \%$ of the total heat related mortality for this region and period. Heaviside et al used a different heat mortality model based on mean temperature, with different temperature metrics (two-day rolling mean) and associated heat-risk coefficients, and with a lower threshold temperature of $17.7^{\circ} \mathrm{C}$. Differences may also be attributed to the underlying population data used in the studies that had different spatial resolutions, and the fact that Heaviside et al. did not include age specific mortality calculations. Future work should investigate the sensitivity of mortality estimates to the underlying mortality models, data inputs, and assumptions.

Both dwelling and UHI mortality calculations assume $T_{\max , p}$ exposure at home. While many will be out during the day, mortality is dominated by deaths among the more vulnerable groups, who are more likely to spend the day at home. The modelled adaptations would be difficult to implement across the entirety of the housing stock, and represent the theoretical maximum impact on temperature exposure and health of these interventions. Targeted interventions, for example installing shutters in dwellings inhabited by the most heat-vulnerable (for example nursing homes), may be a more realistic method of reducing heat-related mortality. Similarly, changes in building regulations should require that energy efficient retrofit should be combined with shading or passive cooling strategies in order to reduce overheating risk. Other passive housing adaptations adopted from warmer climates, such as cool roofs and low-emissivity glazing, have not been modelled here but should be assessed in future studies, as well as the practical limitations of various adaptations. Active adaptations, such as $\mathrm{A} / \mathrm{C}$, have the potential to greatly reduce risk, but should be discouraged due to high energy use. Reductions in UHI may be achieved through localised land use changes, for example greening, but are more 
difficult to target at the most heat-vulnerable, and may require more aggressive planning strategies.

The protective effect of shutters decreased at increasing outdoor temperatures, but still offered an appreciable reduction in risk. Nonetheless, long-term adaptations to buildings and land use to reduce temperature exposures need to be done in conjunction with other short-term measures to reduce exposure, such as providing hot weather advice and arranging cooling centres, or air-conditioned buildings, where vulnerable members of the public may gather during hot weather. Cooling retreats - such as rooms in houses or multi-dwelling buildings with $A / C$ may also reduce risk, albeit with an increased energy expenditure. While the impacts of shutters and UHI have been modelled independently due to the lack of spatial data in the EHS, they are not mutually exclusive and when applied in concert may provide significant reduction in heat exposure and subsequent mortality. The results described here may provide insight into passive adaptation to heat beyond the West Midlands to other temperate regions with similar housing stocks, supported by the wide availability of temperature-mortality models for different regions worldwide (e.g. Gasparrini et al, 2015).

As with any modelling study there are various uncertainties with the model results. The building simulations were implemented using a range of assumptions about personal behaviour (e.g. in relation to occupancy patterns and window opening), which could be important modifiers of indoor temperatures and personal exposures. The modelled indoor temperatures have been shown to be in broad agreement with a large dataset of monitored indoor temperature data (Symonds et al, 2016b), with dwelling variants such as top-floor flats and those with higher levels of insulation typically showing higher indoor temperatures. There is currently a lack of monitored temperature data on shuttered UK housing, however the effectiveness of shutters in reducing temperature exposure are in line with those modelled in earlier studies (Gupta and Gregg, 2012; Porritt et al, 2012).

Calculations of heat-related mortality risk were based on the exposure-response functions derived from studies of mortality in relation to outdoor temperature. It is an assumption that the same risk function applies to exposures of individuals in their own homes, but in the absence of direct evidence about the risks of indoor temperature exposures, it seems a reasonable proxy. This assumption does not account for the possibility that people indoors may have a wider range of methods to cope with heat stress, such as removing clothes or taking cold showers. However, even if the shape of the function is not precisely known, risk will be closely related to exposure to high temperatures, and the comparisons of the three sets of adaptation provide fairly clear indication of the approximate magnitude of the temperature changes associated with them.

\section{CONCLUSIONS}

This paper has described the application of a heat risk model to the housing stock and population of the West Midlands, UK, and estimated how adaptations to the housing stock may alter the risk of heat-related mortality. Results indicate that installing shutters could reduce summertime heat-related mortality by $30-60 \%$ depending on the climate scenario, while complete energy efficient retrofit may increase heat-related mortality risk by $1-14 \%$. Our results show that, of the scenarios modelled here, the UHI is the largest contributor to population average temperature exposure, but not the largest contributor to estimated mortality. Future policies may include the requirement for shutters or external shading in building regulations, and the targeted installation of shutters, particularly in dwellings with vulnerable, elderly occupants. 


\section{ACKNOWLEDGEMENTS}

The research was funded by the National Institute for Health Research Health Protection Research Unit (NIHR HPRU) in Environmental Change and Health at the London School of Hygiene and Tropical Medicine in partnership with Public Health England (PHE), and in collaboration with the University of Exeter, University College London, and the Met Office. The views expressed are those of the author(s) and not necessarily those of the NHS, the NIHR, the Department of Health or Public Health England.

\section{REFERENCES}

Armstrong, B.G., Chalabi, Z., Fenn, B., Hajat, S., Kovats, S., Milojevic, A., Wilkinson, P., 2011. Association of mortality with high temperatures in a temperate climate: England and Wales. Journal of Epidemiology and Community Health 65, 340-5. doi:10.1136/jech.2009.093161

Beizaee, A., Lomas, K.J., Firth, S.K., 2013. National survey of summertime temperatures and overheating risk in English homes. Building and Environment 65, 1-17. doi:10.1016/j.buildenv.2013.03.011

Chen, F., Kusaka, H., Bornstein, R., Ching, J., Grimmond, C.S.B., Grossman-Clarke, S., Loridan, T., Manning, K.W., Martilli, A., Miao, S., Sailor, D., Salamanca, F.P., Taha, H., Tewari, M., Wang, X., Wyszogrodzki, A.A., Zhang, C., 2011. The integrated WRF/urban modelling system: development, evaluation, and applications to urban environmental problems. International Journal of Climatology 31, 273-288.

doi:10.1002/joc.2158

DCLG, 2011. English Housing Survey 2010-2011. Department for Communities and Local Government, London, UK. URL https://discover.ukdataservice.ac.uk/series/?sn=200010

Eames, M., Kershaw, T., Coley, D., 2010. On the creation of future probabilistic design weather years from UKCP09. Building Services Engineering Research and Technology 32, 127-142. doi:10.1177/0143624410379934

ESRI, 2013. ArcGIS 10.1. Environmental Systems Research Institute, Redmond, USA.

Gasparrini, A., Armstrong, B., Kovats, S., Wilkinson, P., 2012. The effect of high temperatures on cause-specific mortality in England and Wales. Occupational and Environmental Medicine 69, 56-61. doi:10.1136/oem.2010.059782

Gasparrini, A., Guo, Y., Hashizume, M., Lavigne, E., Zanobetti, A., Schwartz, J., Tobias, A., Tong, S., Rocklöv, J., Forsberg, B., Leone, M., De Sario, M., Bell, M.L., Guo, L., Wu, C., Kan, H., Yi, S.M., Coelho, M., Saldiva, P., Honda, Y., Kim, H., Armstrong, B. 2015. Mortality risk attributable to high and low ambient temperature: a multicountry observational study. The Lancet, 386:9991, 369-375. https://doi.org/10.1016/S01406736(14)62114-0. 
Gupta, R., \& Gregg, M. 2012. Using UK climate change projections to adapt existing English homes for a warming climate. Building and Environment, 55, 20-42.

Hajat S, Kovats RS, Lachowycz K. 2007. Heat-related and cold-related deaths in England and Wales: who is at risk? Occupational and Environmental Medicine 64,93100.

Hajat, S., Vardoulakis, S., Heaviside, C., Eggen, B., 2014. Climate change effects on human health: projections of temperature-related mortality for the UK during the 2020s, 2050s and 2080s. Journal of Epidemiology and Community Health 68, 641-8. doi:10.1136/jech-2013-202449

Heaviside, C., 2015. The effects of horizontal advection on the urban heat island in Birmingham and the West Midlands, United Kingdom during a heatwave. Quarterly Journal of the Royal Meteorological Society 141, 1429-1441. doi:10.1002/qj.2452

Heaviside, C., Cai, X.-M., Vardoulakis, S., 2016. Attribution of mortality to the Urban Heat Island during heatwaves in the West Midlands, UK. Environmental Health 15, S27. doi:10.1186/s12940-016-0100-9

Heaviside, C., Macintyre, H. L., Vardoulakis, S., 2017. The Urban Heat Island: Implications for health in a changing environment. Current Environmental Health Reports 4: 296-305. 10.1007/s40572-017-0150-3.

Johnson, H., Kovats, R., McGregor, G., 2005. The impact of the 2003 heat wave on daily mortality in England and Wales and the use of rapid weekly mortality estimates. Eurosurveillance 10, 168-171. https://doi.org/10.2807/esm.10.07.00558-en

Martilli, A., Clappier, A., Rotach, M.W., 2002. An Urban Surface Exchange Parameterisation for Mesoscale Models. Boundary-Layer Meteorology 104, 261-304. doi:10.1023/A:1016099921195

Mavrogianni, A., Wilkinson, P., Davies, M., Biddulph, P., Oikonomou, E., 2012. Building characteristics as determinants of propensity to high indoor summer temperatures in London dwellings. Building and Environment 55, 117-130. doi:10.1016/j.buildenv.2011.12.003

Murphy, J., Sexton, D., Jenkins, G., Boorman, P., Booth, B., Brown, K., Clark, R., Collins, M., Harris, G., Kendon, E., 2009. UKCP09 Climate change projections, Met Office Hadley Centre. Exeter. URL:

http://ukclimateprojections. metoffice.gov.uk/media.jsp?mediaid=87894\&filetype $=$ p $\underline{\mathrm{df}}$

Oke, TR. 1982. The energetic basis of the urban heat island (Symons Memorial Lecture, 20 May 1980). Quarterly Journal of the Royal Meteorological Society. 108: $1-24$.

ONS, 2011. 2011 Census: Aggregate data (England and Wales). Office for National Statistics, London, UK. URL https://census.ukdataservice.ac.uk/get-data/aggregatedata 
ONS, 2013. Deaths registered in England and Wales, 2012 [WWW Document]. Office for National Statistics, London, UK. URL

http://www.ons.gov.uk/ons/rel/vsob1/mortality-statistics--deaths-registered-inengland-and-wales--series-dr-/2012/dr-tables-2012.xls

ONS, 2005. United Kingdom Time Use Survey. Office for National Statistics, London, UK. URL https://discover.ukdataservice.ac.uk/series/?sn=2000054

ONS, 2001. 2001 Census: Census Output Area Statistics (England and Wales). Office for National Statistics, London, UK. URL: https://census.ukdataservice.ac.uk/getdata/aggregate-data

PHE, 2015. Heatwave Plan for England 2015. Public Health England, London, UK. URL https://www.gov.uk/government/uploads/system/uploads/attachment data/file/42 9384/Heatwave Main Plan 2015.pdf

Porritt, S. M., Cropper, P. C., Shao, L., \& Goodier, C. I. 2012. Ranking of interventions to reduce dwelling overheating during heat waves. Energy and Buildings, 55, 16-27.

Schaul, T., Bayer, J., Wierstra, D., Sun, Y., Felder, M., Sehnke, F., Rückstieß, T., Schmidhuber, J., 2010. PyBrain. Journal of Machine Learning Research 11, 743-746.

Symonds, P., Taylor, J., Chalabi, Z., Mavrogianni, A., Davies, M., Hamilton, I., Vardoulakis, S., Heaviside, C., Maclntyre, H., 2016. Development of an adaptable England-wide indoor overheating and air pollution model. Journal of Building Performance Simulation 9, 606-619. doi:10.1080/19401493.2016.1166265

Symonds, P., Taylor, J., Mavrogianni, A., Davies, M., Shrubsole, C., Hamilton, I., Chalabi, Z., 2016. Overheating in English dwellings: comparing modelled and monitored large-scale datasets. Building Research \& Information 45, 195-208. doi:http://dx.doi.org/10.1080/09613218.2016.1224675

Taylor, J., Wilkinson, P., Davies, M., Armstrong, B., Chalabi, Z., Mavrogianni, A., Symonds, P., Oikonomou, E., Bohnenstengel, S.I., 2015. Mapping the effects of Urban Heat Island, housing, and age on excess heat-related mortality in London. Urban Climate 14, 517-528. doi:10.1016/j.uclim.2015.08.001

Taylor, J., Mavrogianni, A., Davies, M., Das, P., Shrubsole, C., Biddulph, P., Oikonomou, E., 2015. Understanding and mitigating overheating and indoor PM2.5 risks using coupled temperature and indoor air quality models. Building Services Engineering Research and Technology 36, 275-289. doi:10.1177/0143624414566474

Vardoulakis, S., Dimitroulopoulou, C., Thornes, J., Lai, K.-M., Taylor, J., Myers, I., Heaviside, C., Mavrogianni, A., Shrubsole, C., Chalabi, Z., Davies, M., Wilkinson, P., 2015. Impact of climate change on the domestic indoor environment and associated health risks in the UK. Environment international 85, 299-313.

doi:10.1016/j.envint.2015.09.01 